\title{
OS ELEMENTOS DE CONEXÃO EM DIREITO TRIBUTÁRIO \\ INTERNACIONAL: DEFININDO O SIGNIFICADO DE "RESIDÊNCIA" PARA PESSOA FÍSICA E CONTRIBUIÇÃO DO DIREITO COMPARADO
}

\author{
CONNECTING FACTORS IN INTERNATIONAL TAX LAW: THE DEFINITION PROCESS OF \\ "RESIDENCE" CONCERNING NATURAL PERSON AND COMPARATIVE LAW CONTRIBUTION
}

Lucas Augusto Ponte Campos*

\begin{abstract}
Resumo:
O presente artigo tem por objetivo dar linhas gerais sobre a conceituação de "residência" das pessoas físicas enquanto elemento de conexão e sua relevância ao Direito Tributário Internacional, expondo a questão segundo enfoque do Direito Comparado.

Palavras-chaves: Direito Tributário Internacional. Direito Comparado. Elementos de conexão. Residência.

Abstract:

This essay is focused in set general lines about the conceptualization of legal element "residence" and its relevancy to International Tax Law, through exposition of the question presented under Comparative Law perspective.
\end{abstract}

Keywords: International Tax Law. Comparative Law. Legal element. Residence.

1. Preâmbulo: os elementos de conexão e o Direito Tributário Internacional

A importância do estudo dos elementos de conexão na seara jurídica tributária deriva diretamente da necessidade do estudo da validade e da eficácia que se atribui à norma tributária em sua extraterritorialidade, isto é, quando a constrição normativa é imposta sobre fatos geradores diferenciados dos que corriqueiramente denunciamos como passíveis de serem atingidos por um exercício específico de soberania.

De fato, o entendimento dos critérios, ou elementos, de conexão é essencial à supressão do fenômeno da bitributação. Esta é uma questão que vem sendo estudada desde a moderna configuração de comunidade das nações, com o advento da Sociedade, ou Liga, das Nações, no fim da Primeira Guerra Mundial, ${ }^{1}$ reiterando-se, ao longo do tempo transcorrido, a necessidade de harmonização, a fim de prevenir o fenômeno acima

\footnotetext{
Mestrando em Filosofia e Teoria Geral do Direito na Faculdade de Direito da Universidade de São Paulo; Pós-Graduando lato sensu em Direito Tributário pelo Departamento de Direito Econômico-Financeiro da Faculdade de Direito da Universidade de São Paulo.

1 BRUINS, Einaudi; SELIGMAN, Stamp. Report on Doublé Taxation. Liga das Nações: Genebra, 1923. passim.
} 
citado, ${ }^{2}$ num esforço transnacional constante para maximização da eficácia e justificação normativa dos sistemas tributários nacionais. ${ }^{3}$

Os critérios de conexão participam também do método de conformação das matérias em textos legais coerentes à sistemática tributária. Assim, as normas impositivas dos diversos ordenamentos utilizam critérios de conexão como técnica legislativa viabilizadora da oneração de fatos que transcendem o território. ${ }^{4}$

Conclusão: a dupla tributação emerge de uma disputa entre os objetivos prosseguidos pelos Estados (nomeadamente o de arrecadar receitas e evitar a evasão fiscal, a todo o custo) e os objetivos prosseguidos pelos contribuintes (evitar o agravamento da carga global e os entraves ao desenvolvimento do comércio interestadual); logo, cabe ao Direito Tributário Internacional encontrar os princípios jurídicos que devem proceder a uma ordenação do sistema. ${ }^{5}$

\section{Introdução: Breve análise dos critérios de conexão}

Em decorrência da liberdade de escolha concedida para a elaboração do trabalho, desde que se focalizasse num dos aspectos da abordagem do fenômeno dos elementos de conexão no Direito Tributário Internacional, optou-se por objetivar as normas principiológicas relacionadas à territorialidade, em específico a questão da residência. Ademais, foi determinante na escolha deste ponto específico a maturação do debate acerca da conceituação de "residência" das pessoas física e jurídica na seara internacional.

A fim de localizar o elemento de conexão "residência" entre os demais critérios, proceder-se-á com um rápido estudo dos mesmos. A oportunidade desta análise introdutória é justificada pela necessidade de pontuar as peculiaridades de cada um dos elementos de conexão em relação ao que se examinará detalhadamente, estabelecendo desde o primeiro momento a natureza do critério eleito para aprofundamento, apontandose as diferenças e semelhanças em suas influências na configuração da relação obrigacional tributária.

\footnotetext{
2 DOURADO, Ana Paula. Princípios de direito tributário internacional. p. 27-28. Disponível em: <http:// www.esaf.fazenda.gov.br/.../monografias-1998/modulo-A/PRINCIPIOS-DE-DIREITO-TRIBUTARIOINTERNACIONAL.pdf $>$.

3 ANTÓN, Fernando Serrano. ?Hacia la unificación del derecho tributario para residentes y no residentes? In: TÔRRES, Heleno Taveira (Coord.). Direito tributário internacional aplicado. São Paulo: Quartier Latin, 2005. v. 3, p.64. Cf. o autor: “(...) cuando presentam proyectos de ley u otras normas sobre la tributación de "no nacionales', los Estados precisam de uma conexión relevante com el território, deve existir um nexo definido, algún lazo mínimo entre el Estado y la persona, la propriedad o la transacción que pretende hacer tributar".

4 MOREIRA FILHO, Aristóteles. Os critérios de conexão na estrutura da norma tributária. In: TÔRRES, Heleno Taveira (Coord.). Direito tributário internacional aplicado. São Paulo: Quartier Latin, 2003. p. 328.

DOURADO, Ana Paula. op.cit. nota 1, p. 29.
} 
Posteriormente, consolidadas as singularidades da apreciação dos elementos de conexão objetos deste estudo, torna-se possível apresentar uma apreciação satisfatória das questões que envolvem o foco do presente ensaio, o critério de conexão residência ou domicílio no Direito Internacional Tributário.

\subsection{Critérios de conexão subjetivos (personal fiscal attachments)}

Os critérios de conexão - e aqui tratar-se-ão dos que se relacionam com o fenômeno jurídico tributário - subjetivos são aqueles que identificam na pessoa do contribuinte o vínculo com o sistema a que pertence à norma tributária. O elemento ou critério de conexão é derivado do desdobramento da situação do sujeito passivo da relação tributária (residência), ou de um dos elementos que compõe a personalidade (nacionalidade). Se tomarmos a técnica da regra-matriz de incidência, ${ }^{6}$ será precisamente no denominado critério pessoal que consigna a conexão pessoal do fato tributável com o sistema, operando a tributação. ${ }^{?}$

\subsubsection{A residência ou domicílio}

A residência é o critério mais utilizado pelos sistemas tributários para tributar fatos além de sua competência territorial ordinária. ${ }^{8} \mathrm{O}$ critério da residência é utilizado pela Legislação brasileira para tributar a renda independentemente do local de produção ou aferição, universalmente (tributação da renda mundial ou worldwide income taxation), segundo os dispositivos presentes nos arts. $3^{\circ}, \S 4^{\circ}$, da Lei n. $7.713 / 88,38$, do RIR/99 (pessoas físicas), e art. 25 da Lei n. 9.249/95 (pessoas jurídicas).

$\mathrm{O}$ conceito de residência para fins fiscais varia de sistema para sistema, como se observará à frente, porém usualmente se reconhece que para pessoas físicas há um determinado prazo de permanência a partir do qual as mesmas passam a adquirir o status de residente dentro de dado território, e para pessoas jurídicas, há os critérios como local de constituição do local da empresa, sede administrativa, local da atividade principal, entre outros.

Há uma relevância no emprego deste critério de conexão em específico: a atribuição de máxima eficácia da norma tributária. Essa eficácia plena do dispositivo se dá pela facilidade maior de coerção dos sujeitos passivos das relações tributárias,

\footnotetext{
CARVALHO, Paulo de Barros. Curso de direito tributário. 12. ed. São Paulo: Saraiva, 1999. passim. MOREIRA FILHO, Aristóteles. op. cit. nota 2, p. 347.

8 MARINO, Giuseppe. La residenza. In: UCKMAR. Victor (Org.). Corso di diritto tributario internazionale: Padova: Cedam, 2002. p. 233, onde se prenunciou "[C]hiarito, dunque, il ruolo fondamentale giocato dalla residenza nell'ambito di um sistema a tassazione mondiale, e nell'ambito di tassazione, occorre ricordare la sua funzione ai fini della 'localizzazione' del reddito".
} 
em decorrência da presença dos mesmos dentro do território da soberania fiscal e jurisdicional. ${ }^{9}$

\subsubsection{A nacionalidade}

A nacionalidade é um vínculo político que se estabelece entre o Estado e o indivíduo, consubstanciando a dimensão pessoal do Estado soberano. ${ }^{10}$ É a partir deste vínculo que a norma fiscal identifica os eventos tributáveis, aí buscando o lastro de efetividade necessário ao Direito. ${ }^{11}$

Cada ordenamento jurídico determina seus critérios para concessão de nacionalidade a indivíduos, sendo que as pessoas físicas ora se ligam a uma dada nacionalidade pelo critério do ius soli, ora pelo ius sanguini; já às pessoas jurídicas soa reservados critérios como o locus lex celebrationis, para constituição da pessoa (Modelo da OCDE). A Lei brasileira aplicável admite dois critérios para a concessão da nacionalidade: ${ }^{12}$ i. sede da pessoa jurídica ser no Brasil; ii. constituição segundo às leis brasileiras.

Entretanto, na seara tributária, são poucos os sistemas legais que adotam esse elemento de conexão para exercer suas bases de exação fiscal, a citar os Estados Unidos, em vista de que o suporte jurídico é extremamente difuso e pouco justificado em critérios positivados (daí sua ocorrência no maior país de tradição de Common Law), sendo qualificado o presente critério como exceção à regra geral do domicílio. ${ }^{13}$

Salienta-se aqui que cabe, analogamente, à hipótese de verificação de cidadania o mesmo tratamento jurídico aplicado em caso de apreciação de nacionalidade, podendo ser a primeira também um elemento conectivo, inclusive nos mesmos termos e efeitos da segunda, diferindo as duas do critério de residência. ${ }^{14}$

Assim como o critério de conexão previamente analisado, a nacionalidade também atua na regra-matriz de incidência no critério pessoal do antecedente normativo, assim como também fica imputado a tributabilidade aos fatos ocorridos em qualquer lugar, inclusive no estrangeiro (princípio da universalidade).

\footnotetext{
MOREIRA FILHO, Aristóteles. op. cit. nota 2, p. 348-349.

${ }^{10}$ REZEK, José Francisco. Direito internacional público. São Paulo: Saraiva, 2002. p. 171.

11 MOREIRA FILHO, Aristóteles. op. cit. nota 2, p. 349.

12 Arts. 11, da Lei de Introdução ao Código Civil, e 60, do Decreto n. 2.627/40.

13 TÔRRES, Heleno Taveira. Pluritributação internacional sobre as rendas de empresas. 2. ed. São Paulo: Revista dos Tribunais, 2001. p. 126.

14 MARINO, Giuseppe. La residenza. cit. nota 8, p. 235.
} 


\subsection{Os critérios de conexão objetivos (Economic Fiscal Attachments)}

Estes critérios, ao contrário dos anteriores, se ligam ao fato tributável, não importando a localização do contribuinte, podendo o mesmo estar fora da soberania tributante.

A territorialidade do fato econômico tributável, seja na forma de renda, ou de bens, permite ao Estado tributante perseguir com total efetividade a tributação sobre pessoas situadas extraterritorialmente, do que se permite inferir a praticidade jurisdicional da eleição destes critérios em específico.

Os elementos de conexão abaixo abordados influenciam diretamente sobre o critério espacial da hipótese de incidência da norma tributária, em vista de que estão diretamente relacionados com o local de ocorrência do evento tributável.

\subsubsection{O critério da fonte}

A fonte de uma dada renda é, em linhas gerais, o local de onde se origina a renda. Assim, ao se empregar o critério "fonte" como elemento de conexão, reconhece-se como base para tributação o fato de a renda ser auferida dentro de uma dada jurisdição territorial, desconsiderando-se o fato daqueles que recebem estarem fisicamente fora.

Entende-se que existam duas regras, quando surge a questão de que se a "fonte" seria a da fonte de pagamento ou local de produção de onde se deriva a renda: 15 i. utiliza-se como critério primário, preceito geral, a eleição do local de produção, e neste se poderá exercer a exação; ii. se a lei exigir, incidir-se-á a tributação sobre a fonte de pagamento, derrogando preceito acima.

Se observarmos o que dispõe o RIR/99, em seus arts. 682 a 716, manifestamente reconhece-se que existe a possibilidade da ocorrência do critério perscrutado e sua influência sobre a regra-matriz de incidência na função espacial de sua hipótese.

\subsubsection{O critério real ou da situação do bem}

O critério de conexão real realiza, vinculativamente, o fato econômico da propriedade, sua transferência inter vivos ou mortis causa, ou a renda dela decorrente, pelo local do bem, ao sistema do território. ${ }^{16}$

\footnotetext{
${ }^{15}$ UCKMAR, Victor. Corso di diritto tributario internazionale. Padova: Cedam, 1999. p. 12.

${ }^{16}$ MOREIRA FILHO, Aristóteles. op.cit. nota 2, p. 352.
} 
Assim como no caso do critério específico anterior (fonte), também é relevante o dado de que a alta carga de efetividade da norma tributária é notada em decorrência da possibilidade do Fisco mais facilmente constranger, através dos bens presentes em sua jurisdição territorial, em caso de eventual desatendimento da obrigação tributária.

Este critério de conexão sob estudo, correntemente, é utilizado nos tributos sobre propriedade imobiliária, e sobre a renda e a sucessão, quando tenham como objeto bens imóveis.

Tanto o Imposto Predial e Territorial Urbano (IPTU), quanto o Imposto Sobre Transmissão Causa Mortis ou Doação (ITCMD), exemplificativamente, se impõem sob o critério de conexão da situação do bem, determinando marcadamente a feição espacial da hipótese tributária.

\subsubsection{O critério da origem}

O critério de conexão da origem é visto nas operações com mercadorias e serviços. O que se objetiva é o gravame fiscal do fato econômico "operações" pelo reconhecimento da origem das mercadorias e serviços no território do Estado tributante.

Cabe salientar que onera fundamentalmente as operações de exportação, o que confronta os modelos exportadores vigentes no cenário mundial, motivo pelo qual se encontra seu emprego hoje bem resumido aos sistemas nacionais, de modo que só tem sido utilizado em sua feição parafiscal. ${ }^{17}$

O emprego deste elemento de conexão é tão efetivo quanto os demais critérios objetivos, pelo fato de que é facilitada a constrição de valores, a bem da efetividade da legislação tributária pertinente. Tal efetividade se dá porque é possível exigir tributo fazendo-o incidir sobre a própria operação de exportação, agregando custo ao produto ou serviço a ser vendido.

O Imposto sobre Serviços (ISS), relativamente àqueles realizados no Exterior (art. 156, III, da CF/88 e Dec. Lei n. 406/68), exempli gratia, ilustra caso onde há a utilização do critério, sob comento para identificar a possibilidade da prática da tributabilidade.

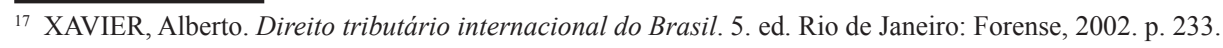




\subsubsection{O critério do destino}

O critério de conexão do destino vincula a operação internacional com bens e serviços, enquanto fatos econômicos tributáveis, com o sistema tributante, a partir do destino da operação, localizado dentro da jurisdição territorial do Estado tributante. ${ }^{18}$

A localização do destinatário das operações de bens e serviços, o importador, dentro do território do tributante, é que confere a efetividade necessária à tributação nestes casos.

O sistema tributário brasileiro adota o critério de conexão do destino na tributação da importação pelo Imposto sobre a Circulação de Mercadorias e Serviços (ICMS), com base no art. 155, $\$ 2^{\circ}$, IX, “ $a$ ", da CF; pelo Imposto sobre Produtos Industrializados (IPI), segundo disposto na Lei n. 4.502/64 (art. $4^{\circ}$, I) e Regulamento do IPI, art. $9^{\circ}$, I; e pelo próprio Imposto de Importação, baseado no art. 153, I, da CF.

Dispensável apontar que o elemento de conexão em apreciação influencia na Hipótese de Incidência dos tributos em seu critério espacial, visto que, apesar de a operação ter início fora do território, conclui-se dentro do território, daí "destino".

3. Estudo sobre o critério da residência e domicílio no que toca à tributação das pessoas físicas

O fato de uma pessoa, seja ela física ou jurídica, ter uma vinculação fiscal com um ente tributante não é constituído ex nihillo. Assim, o exame do critério de conexão da residência é essencial em função de que um dado Estado, no intuito de instituir tributação, deve, a bem dos princípios gerais de Direito Tributário, guardar em relação ao contribuinte qualquer relação justificadora da instituição da exação. ${ }^{19}$

Constitui-se foco do presente estudo abordar esta questão da residência e do domicílio em relação às pessoas físicas.

\footnotetext{
${ }_{18}$ MOREIRA FILHO, Aristóteles. op. cit. nota 2, p. 354.

19 MARINO, Giuseppe. La residenza nel diritto tributário. Padova: Cedam, 1999. p. 291. Cf. o autor: "Si dice Che il legislatore tributário non pio assumere a pressuposto d'imposta fatti privi di ogni collegamento, sai oggetivo Che soggetivo, com il território nazionale. Piuttosto, deve scegliere fatti Che presentino um ragionevole legame com il território e l'ordinamento dello Stato, tale da essere sucettibile di valutazione in termini di capacità contributiva".
} 
3.1. Conceito de residência e domicílio nos sistemas tributários: Direito Comparado

3.1.1. Diferenças e semelhanças entre os conceitos específicos de residência e domicílio: concepções subjetivista e objetivista

A distinção fundamental que se faz dos conceitos de residência e domicílio, de acordo com a doutrina, seria o caráter de maior período de presença, em certo território, do segundo, somada a intenção de permanência.

Em contraponto a esta perspectiva de oposição entre os conceitos em comento, alguns sistemas tributários não estabelecem marcos diferenciais, adotando uma concepção mais objetiva, fundando uma visão diversa daquela exposta acima - a qual traz à consideração um possível elemento subjetivo-volitivo que diferenciaria residência e domicílio. ${ }^{20}$

Na prática tributária, enfim, a distinção entre domicílio e residência não é tão relevante, ${ }^{21}$ ao contrário do que se observa na área civilista, bem como os conceitos em um e outro ramo do Direito por vezes não são os mesmos. ${ }^{22}$

\subsubsection{Conceitos de residência}

Para que seja desenvolvida uma análise crítica sustentável do conceito de residência para o Direito Tributário Internacional, dado que não se observa a prevalência de um International Standard, nos termos dos esforços da OCDE, faz-se necessária uma abordagem de Direito Comparado do instituto.

Direito italiano. O sistema tributário se escora na definição presente na lei civil, caso não exista inscrição do sujeito passivo pessoa física em lista da Pasta Fazendária ("anagrafi della popolazione"), desde pronto estabelecendo a existência de um critério fiscal (art. 2, §2 , Lei fiscal relativa ao Imposto de Renda, d.p.r. 917/22.12.1986), ${ }^{23}$ apartado do cível (art. 43 do Código Civil italiano). Ainda, o sistema italiano reconhece

\footnotetext{
${ }^{20}$ MOREIRA JR, Gilberto de Castro. Bitributação internacional e elementos de conexão. São Paulo: Aduaneiras, 2003. p. 147. Ali se comenta a oposição de concepção subjetiva e objetiva: "Pela concepção subjetivista, a aquisição da residência é feita pela junção da permanência física em determinado local (corpus), com a vontade do indivíduo de se tornar residente daquele país (animus). No caso da concepção objetivista, a aquisição da residência é feita só com a presença física do indivíduo no território do país, apenas fixando um prazo para que a permanência se converta em residência".

${ }^{21}$ TÔRRES, Heleno Taveira. op. cit. nota 13, p. 127.

${ }^{22}$ MELIS, Giuseppe. La nozione di residenza fiscale delle persone fisiche nell'ordinamento tributario italiano. Roma: Luiss/Quasar, 1994. passim. Nesta obra o autor apresenta extensa comparação entre os conceitos presentes nas leis civis e tributárias, num exercício de direito comparado, e concluí que não há congruência entre os institutos nos ramos do Direito abordados.

${ }^{23}$ MARINO, Giuseppe. La residenza. cit. nota 8, p. 236.
} 
como requisito para que se figure na tal lista o fato de residir em solo italiano por, ao menos, 183 dias do calendário solar, dado que se repetirá em outros ordenamentos jurídicos, como se observará a seguir.

Direito inglês. Já no Direito inglês se sustenta o conceito de ordinary residence, isto é, onde o indivíduo habitualmente tem sua moradia, ${ }^{24}$ sendo esta elaboração derivada do Direito costumeiro. ${ }^{25}$ A diferença naquele Direito existente entre domicile of choice (domicílio de escolha) e domicile of origin (domicílio de origem) suplanta a simplicidade da abordagem dada pelo Direito continental.

Se observado que houve, materialmente, a renúncia ao domicílio da escolha, automaticamente o indivíduo se presume ligado ao domicílio de origem. ${ }^{26}$ No sistema tributário britânico, aos residentes e não-domiciliados no Reino Unido (pessoas físicas) é imposto tributação sobre a renda obtida ali e sobre remessas que entram lá, não se aplicando o princípio do worldwide income, o qual só é válido àqueles que residem e são domiciliados..$^{27} \mathrm{O}$ mesmo regime se aplica aos ganhos de capital. ${ }^{28}$ Como citado, também é presente no Direito inglês o prazo de 183 dias para estabelecimento de residência.

Direito francês. O sistema tributário francês reconhece basicamente quatro características que fazem evidente a situação de domicílio fiscal: i. origem; ii. escolha; iii. Atividade profissional em solo francês; iv. Interesse econômico. ${ }^{29}$

Na França, tal com ocorre no Reino Unido, há uma diferenciação entre aqueles que residem e os que são domiciliados em relação à imposição tributária sobre rendas mundiais, cabendo somente aos residentes tributação sobre a renda mundial. ${ }^{30}$ Persiste naquele ordenamento a regra de que existe o conceito civil e o tributário de residência. ${ }^{31}$

\footnotetext{
${ }^{24}$ XAVIER, Alberto. op. cit. nota 15 (5. ed., 1998), p. 253-254. Cf. o Autor: “(...) [o Direito inglês] atribui um relevo todo especial a noção de domicile of origin, dificultando o acesso ao domicile of choice - distingue os seus residentes domiciliados e os seus residentes não-domiciliados, aplicando aos primeiros o princípio do worldwide income, e tributando os segundos apenas pelos rendimentos externos remetidos para o seu território (remittance basis). O conceito de domicílio no Direito inglês se constrói a partir das noções de domicile of origin e de domicile of choice: a primeira respeita a todos os nacionais britânicos, nascidos no Reino Unido; a segunda, ao país com o qual a pessoa estabeleceu os laços mais estreitos, tornando-se sua 'pátria de adoção' (...). No Direito francês também distingue a simples residência habitual do domicílio. Neste caso, o princípio da universalidade é aplicado apenas aos residentes domiciliados, ao passo que os residentes não domiciliados estão sujeitos apenas à tributação dos rendimentos oriundos de fonte francesa".

${ }^{25}$ Caso Winans v. Attorney General (1904), A.C. 290.

${ }^{26}$ Caso Fielden v. IRC (1965), T.R. 221.

${ }^{27}$ Parágrafos 65 (5) e 132 (5) do Income and Corporation Taxes Act, de 1988; Caso Harmel v. Wright (1973) 49 T.C. 149.

28 Parágrafo 12 (1) do Taxation of Chargeable Gains Act, de 1992.

29 Art. 4 B do Code General dês Impots.

${ }^{30}$ Art. 4 A do Code General dês Impots.

31 Decisões n. 69113 e 69114, Conselho de Estado, de 24.11.1967.
} 
Direito alemão. Na legislação tributária tem-se categorizada a questão da residência (Wohnsitz). Pode ser passível de tributação aquele que tiver um local por residência ou que tenha disposição de utilizá-lo como tal. ${ }^{32}$ A permanência deve ser de, no mínimo, seis meses e não se deve reconhecer a característica da estada como sendo de passagem. ${ }^{33}$

Direito espanhol. Na Espanha, determina-se a residência nos termos da lei relativa ao imposto de renda das pessoas físicas, na qual se reconhece o vínculo pela habitualidade, percebidos o prazo de seis meses; ou a existência de elementos de interesse profissional, bem como motivação econômica. ${ }^{34}$ A doutrina espanhola reconhece que o conceito de bem beneficia a sanha arrecadatória, uma vez que a regra da habitualidade é substituível pela justificação profissional/econômica. ${ }^{35}$

Direito brasileiro. O ordenamento pátrio, em comparação com os demais sistemas tributários abordados, apresenta consonância com aqueles que reconhecem a diferenciação entre exercício de atividade profissional/econômica e residência, tributando a pessoa física em ambos os casos, porém com uma diversidade de formalidades - e peculiaridades derivadas - no que toca a questão dos tipos de visto. ${ }^{36}$

Assim como em outros países, a definição civil de residência, ou domicílio, não influencia na perspectiva tributária da questão da residência, ou domicílio. Para fins de tributação, reconhece-se como domicílio fiscal a residência habitual, não se fazendo qualquer ressalva quanto ao animus de habitar. ${ }^{37}$

\footnotetext{
$32 \S 8$ da Abgabenordnung ("Einen Wohnsitz hat jemand dort, wo er eine Wohnung unter Umstanden innhat, die darauf schliessen lassen, das ser die Wohnung biebehalten und benuzt wird").

${ }^{33} \S 9$ da Abgabenordnung.

${ }^{34}$ Art. 13 da Lei n. 18/1991.

${ }^{35}$ MARINO, Giuseppe. La residenza. cit. nota 8, p. 244.

${ }^{36}$ Em caso de visto permanente, aplica-se o disposto no art. 61, do Decreto-Lei n. 5.844/1.943, combinado com art. 12 da Lei n. 9.718/1.998., estando o indivíduo sujeito ao Fisco desde a data de seu ingresso no país. Já os estrangeiros com vistos temporários encontram-se submetidos ao mesmo texto do art. 12 supra citado, não distinguindo a lei federal qualquer termo de intenção de permanência para que exista a exação prevista, tendo as rendas o mesmo tratamento dado às dos residentes/domiciliados.

${ }^{37}$ Art. 28 do Dec. n. 3.000/1.999 (RIR): "Considera-se como domicílio fiscal da pessoa física a sua residência habitual, assim entendido o lugar em que ela tiver uma habitação em condições que permitam presumir intenção de mantê-la (Decreto-Lei n. 5.844, de 1943, art. 171).

$\S 1^{\circ}$ No caso de exercício de profissão ou função particular ou pública, o domicílio fiscal é o lugar onde a profissão ou função estiver sendo desempenhada (Decreto-Lei n. 5.844, de 1943, art. 171, § $1^{\circ}$ ).

$\S 2^{\circ}$ Quando se verificar pluralidade de residência no País, o domicílio fiscal será eleito perante a autoridade competente, considerando-se feita a eleição no caso da apresentação continuada das declarações de rendimentos num mesmo lugar (Decreto-Lei n. 5.844, de 1943, art. 171, § $2^{\circ}$ ).

$\S 3^{\circ} \mathrm{A}$ inobservância do disposto no parágrafo anterior motivará a fixação, de ofício, do domicílio fiscal no lugar da residência habitual ou, sendo esta incerta ou desconhecida, no centro habitual de atividade do contribuinte (Decreto-Lei n. 5.844, de 1943, art. 171, § $3^{\circ}$, e Lei n. 5.172, de 1966, art. 127, inciso I).

$\S 4^{\circ}$ No caso de ser impraticável a regra estabelecida no parágrafo anterior, considerar-se-á como domicílio do contribuinte o lugar onde se encontrem seus bens principais, ou onde ocorreram os atos e fatos que deram origem à obrigação tributária (Lei n. 5.172 , de 1966, art. 127, § $1^{\circ}$ ).
} 
Adquirido o tratamento de residente, sem distinção de conceitual de domicílio, todas as rendas relativas ao indivíduo são passíveis de tributação, inclusive a renda mundial, sendo que mesmo não-residentes, desde o momento primeiro de sua estada no Brasil, são tributados em suas aplicações financeiras e ganhos de capital. ${ }^{38}$

$\mathrm{O}$ ordenamento tributário brasileiro confere aos residentes em regime de ausência, desde que não se tenha requerido a certidão de quitação de tributos federais, as mesmas obrigações da esfera tributária imputadas aos residentes. A certidão é o requisito formal necessário para a realização do afastamento da condição de residente, juntamente com a declaração de saída definitiva, em casos de transferência de residência para o Exterior. ${ }^{39}$ Se o ausente adquirir o visto de permanência em outro país, o residente, no Brasil, automaticamente, passa ser qualificado como não-residente. Outra maneira de se ocorrer o desligamento qualitativo de residente é ausência por mais de doze meses, sendo computados todos os rendimentos, segundo o princípio da universalidade até o decurso do prazo em comento para tributação (como se fosse residente ainda). ${ }^{40}$

\subsubsection{Modelo de convenção fiscal sobre o rendimento e o patrimônio}

Segue abaixo o texto do art. $4^{\circ}$, do Modelo de Convenção Fiscal sobre o Rendimento e o Patrimônio:

Article 4

\section{RESIDENT}

1. For the purposes of this Convention, the term "resident of a Contracting State

means any person who, under the laws of that State, is liable to tax therein by reason of his domicile, residence, place of management or any other criterion of a similar nature, and also includes that State and any political subdivision or local authority thereof. This term, however, does not include any person who is liable to tax in that State in respect only of income from sources in that State or capital situated therein.

2. Where by reason of the provisions of paragraph 1 an individual is a resident of both

\footnotetext{
$\S 5^{\circ}$ A autoridade administrativa pode recusar o domicílio eleito, quando impossibilite ou dificulte a arrecadação ou a fiscalização do imposto, aplicando-se então as regras dos $\S \S 3^{\circ}$ e $4^{\circ}$ (Lei n. 5.172, de 1966, art. 127, $\S$ $\left.2^{\circ}\right)$.

$\S 6^{\circ} \mathrm{O}$ disposto no $\S 3^{\circ}$ aplica-se, inclusive, nos casos em que a residência, a profissão e as atividades efetivas estão localizadas em local diferente daquele eleito como domicílio."

38 Art. 78, incisos I a III, da Lei n. 8.981/1.995 e art. 18 da Lei n. 9.249/1995.

39 Art. 17 da Lei n. 3.470/1958.

${ }^{40}$ Art. 12 da Lei n. 9.718/1998; Art. $7^{\circ}$ da Lei n. 9.779/1998.
} 
Contracting States, then his status shall be determined as follows:

a) he shall be deemed to be a resident only of the State in which he has a permanent home available to him; if he has a permanent home available to him in both States, he shall be deemed to be a resident only of the State with which his personal and economic relations are closer (centre of vital interests);

$b)$ if the State in which he has his centre of vital interests cannot be determined, or if he has not a permanent home available to him in either State, he shall be deemed to be a resident only of the State in which he has an habitual abode;

c) if he has an habitual abode in both States or in neither of them, he shall be

deemed to be a resident only of the State of which he is a national;

d) if he is a national of both States or of neither of them, the competent authorities of the Contracting States shall settle the question by mutual agreement.

3 . Where by reason of the provisions of paragraph 1 a person other than an individual is a resident of both Contracting States, then it shall be deemed to be a resident only of the State in which its place of effective management is situated." 41

O Modelo de Convenção da OCDE considera como sinônimos os termos residência e domicílio, em seu art. $4^{\circ}, \S 1^{\circ}$, do Modelo de Convenção Fiscal sobre o Rendimento e o Patrimônio. ${ }^{42}$

O Modelo também traz em seu a possibilidade de tie-break, isto é, a solução de situações de bitributação. Sua aplicação, entretanto, é dificultada pela diversidade de interpretações possíveis de seu conteúdo pelos legisladores internos; por outro lado, deve ser reconhecido o esforço de harmonização e possibilidade de futura unificação dos conceitos de residência/domicílio, com vistas à eliminação dos fenômenos de pluritributação. ${ }^{43}$

São Paulo, dezembro de 2008.

\footnotetext{
${ }^{41}$ Extraído do sítio eletrônico da OCDE: <http://www.oecd.org/document/37/0,2340,en_2649_201185_ 1913957_1_1_1_1,00.html>.

${ }^{42}$ Comitê de Assuntos Fiscais da OCDE. Modelo de convenção fiscal sobre o rendimento e o patrimônio. Lisboa: Centro de Estudos Fiscais, 1995. p. 26-27.

${ }^{43}$ MARINO, Giuseppe. La residenza. cit. nota 6, p. 246-247.
} 


\section{Referências}

ANTÓN, Fernando Serrano. ?Hacia la Unificación Del Derecho Tributario para Residentes y no Residentes? In: TÔRRES, Heleno Taveira (Coord.). Direito tributário internacional aplicado. São Paulo: Quartier Latin, 2005.

BRUINS, Einaudi; SELIGMAN, Stamp. Report on Doublé Taxation. Liga das Nações: Genebra, 1923.

CARVALHO, Paulo de Barros. Curso de direito tributário. 12. ed. São Paulo: Saraiva, 1999.

COMITE DE ASSUNTOS FISCAIS DA OCDE, Modelo de Convenção Fiscal sobre o Rendimento e o Patrimônio, Lisboa: Centro de Estudos Fiscais, 1995.

DOURADO, Ana Paula. Principios de direito tributário internacional. Disponível em: $<$ http://www. esaf.fazenda.gov.br/.../monografias-1998/modulo-A/PRINCIPIOS-DE-DIREITO-TRIBUTARIOINTERNACIONAL.pdf>.

MARINO, Giuseppe. La Residenza. In UCKMAR, Victor (Org.). Corso di diritto tributario internazionale. Padova: Cedam, 2002.

MARINO, Giuseppe. La residenza nel diritto tributário. Padova: Cedam, 1999.

MELIS, Giuseppe. La nozione di residenza fiscale delle persone fisiche nell'ordinamento tributario italiano. Roma: Luiss/Quasar, 1994.

MOREIRA FILHO, Aristóteles. Os critérios de conexão na estrutura da norma tributária. In: TÔRRES, Heleno Taveira (Coord.). Direito tributário internacional aplicado. São Paulo: Quartier Latin, 2003.

MOREIRA JR., Gilberto de Castro. Bitributação internacional e elementos de conexão. São Paulo: Aduaneiras, 2003.

REZEK, José Francisco. Direito internacional público. São Paulo: Saraiva, 2002.

TÔRRES, Heleno Taveira. Pluritributação internacional sobre as rendas de empresas. São Paulo: RT, 2001.

UCKMAR, Victor. Corso di diritto tributario internazionale. Padova: Cedam, 1999.

XAVIER, Alberto. Direito tributário internacional do Brasil. 5. ed. Rio de Janeiro: Forense, 2002. 